\title{
Wall conditioning in fusion devices with superconducting coils
}

\author{
T. Wauters ${ }^{1}$, D. Borodin ${ }^{2}$, R. Brakel ${ }^{3}$, S. Brezinsek ${ }^{2}$, KJJ Brunner $^{3}$, J. Buermans ${ }^{1}$, S. \\ Coda $^{4}$, A. Dinklage ${ }^{3}$, D. Douai ${ }^{5}$, O. Ford ${ }^{3}$, G. Fuchert ${ }^{3}$, A. Goriaev ${ }^{1,6}$, H. Grote ${ }^{3}$, A. \\ Hakola $^{7}$, E. Joffrin ${ }^{5}$, J. Knauer ${ }^{3}$, T. Loarer ${ }^{5}$, H. Laqua ${ }^{3}$, A. Lyssoivan ${ }^{1}$, V. M oiseenko ${ }^{8}$, \\ D. M oseev ${ }^{3}$, J. Ongena ${ }^{1}$, K. Rahbarnia ${ }^{3}$, D. Ricci ${ }^{9}$, V. Rohde ${ }^{10}$, S. Romanelli ${ }^{11}$, S. \\ Sereda $^{2}$, T. Stange ${ }^{3}$, F.L. Tabarés ${ }^{12}$, Lilla Vanó ${ }^{3}, 0$. Volzke $^{3}$, E. Wang ${ }^{2}$

\section{ASDEX Upgrade team, TCV Team ${ }^{13}$, EUROfusion MST1 team ${ }^{14}$, W7-X Team, JT-60SA team and JET contributors ${ }^{15}$}

${ }^{1}$ Laboratory for Plasma Physics, LPP-ERM/KMS, B-1000 Brussels, Belgium, Trilateral Euregio Cluster (TEC) Partner.

${ }^{2}$ Forschungszentrum Jülich GmbH, Institut für Energie- und Klimaforschung, Plasmaphysik, 52425 Jülich, Germany

${ }^{3}$ Max-Planck-Institut für Plasmaphysik, Wendelsteinstrasse 1, 17491 Greifswald, Germany

${ }^{4}$ Ecole Polytechnique Fédérale de Lausanne (EPFL), Swiss Plasma Center (SPC), CH-1015 Lausanne, Switzerland

${ }^{5}$ CEA, IRFM, F-13108 Saint Paul Lez Durance, France

${ }^{6}$ Department of Applied Physics, Ghent University, Belgium

${ }^{7}$ VTT Technical Research Centre of Finland, PO Box 1000, FIN-02044 VTT, Finland

${ }^{8}$ Institute of Plasma Physics of the NSC KIPT, Kharkov, Ukraine

${ }^{9}$ Istituto di Fisica del Plasma CNR, 20125 Milano, Italy

${ }^{10}$ Max-Planck-Institut für Plasmaphysik, Boltzmannstrasse 2, 85748 Garching, Germany

${ }^{11}$ CCFE, Culham Science Centre, Abingdon, Oxon, OX14 3DB, United Kingdom

${ }^{12}$ Laboratorio Nacional de Fusion, CIEMAT, 28040, Madrid, Spain

\author{
${ }^{13}$ See author list of S. Coda et al 2019 Nucl. Fusion 59112023 \\ ${ }^{14}$ See author list of B. Labit et al 2019 Nucl. Fusion 59086020 \\ ${ }^{15}$ See the author list of E. Joffrin et al. accepted for publication in Nuclear Fusion Special issue 2019, \\ https://doi.org/10.1088/1741-4326/ab2276
}

E-mail: t.wauters@fz-juelich.de

Received xxxxxx

Accepted for publication $\mathrm{xxxxxx}$

Published xxxxxx

\begin{abstract}
Wall conditioning is essential in tokamak and stellarator research to achieve plasma performance and reproducibility. This paper presents an overview of recent conditioning results, both from experiments in present devices and modelling, in view of devices with superconducting coils, with focus on W7-X, JT-60SA and ITER. In these devices, the coils stay energised throughout an experimental day or week which demands for new conditioning techniques that work in presence of the nominal field, in addition to the proven conditioning methods such as baking, glow discharge conditioning (GDC) and low-Z wall coating through GDC-plasma, which do not work under such condition. The discussed techniques are RF conditioning without plasma current, both in the ion cyclotron and electron cyclotron range of frequencies, and diverted conditioning plasmas with nested magnetic flux surfaces.
\end{abstract}


Similarities and differences between tokamaks and stellarators are highlighted. Finally a conditional tritium recovery strategy for ITER is proposed based on Ion Cyclotron Wall Conditioning and L-mode plasma results from JET, equipped with an ITER-like wall (beryllium main chamber wall and tungsten divertor).

Keywords: wall conditioning, baking, GDC, wall coating, ECRH, ECWC, ICWC, tritium recovery, W7-X, JT-60SA, ITER

\section{Introduction}

Wall conditioning is essential in tokamak and stellarator research. It is relied upon to obtain improved and reproducible plasma performance by (i) reducing the release of impurities from the first wall as a consequence of plasma-surface interactions, and (ii) controlling the recycling of hydrogenic fuel fluxes and hence the plasma density [1]. More specifically, conditioning techniques allow tokamak start-up and recovering from events such as disruptions in a tokamak (often mitigated by gas injection, e.g. argon), radiative collapses in a stellarator or vacuum leaks. Conditioning accelerates the transition from plasma operations in one main plasma element, either a hydrogen isotope or helium, to another and provides access to advanced scenarios. Finally, both JET and ITER, facing a strict safety limit on the in-vessel tritium (T) inventory of $11 \mathrm{~g}$ and $700 \mathrm{~g}$ of $\mathrm{T}$ respectively, rely on conditioning techniques for tritium removal from the plasma-facing materials [2].

With the progress in fusion research, new conditioning challenges appear. New devices, equipped with superconducting magnetic field coils, restrict the use of proven conditioning methods such as baking and glow discharge conditioning (GDC), including the application of wall coatings through GDC-plasma. Baking requires deenergised field coils for technical reasons while GDC is incompatible with the magnetic field for physics reasons. Superconducting coils typically withstand a limited amount of charging cycles from zero to full current throughout their lifetime. New conditioning techniques are therefore being developed to ensure good plasma performance in long pulses and to mitigate the tritium inventory build-up throughout an experimental day or week during which the superconducting coils remain energised.

Indeed, while the permanent retention rate of fuel in JET, equipped with an ITER-like wall (ILW) since 2011 [3] (beryllium main chamber wall and tungsten divertor), is reduced by a factor of $\sim 18$ with respect to operation with carbon-based materials [4], the rates may still lead to an unacceptable tritium inventory build-up when extrapolated to ITER. Uncertainties remain on the absolute rates. Post mortem analysis finds permanent retention rates for deuterium (D) of
$5.7 \times 10^{18}$ D.s ${ }^{-1}[5]$ while gas balance analysis result in rates of $0.2-1.5 \times 10^{20} \mathrm{D}^{-1}{ }^{-1}$ [4], [6] or higher as discussed in section 3.3. Long term outgassing [4] and retention in remote areas may explain the difference between post mortem analysis and gas balance analysis, while the reason for the spread in the latter is sought in the strong dependence of retention on the discharge scenario and the wall loading. Extrapolating the worst case retention rate $\left(1.5 \times 10^{20}\right.$ D.s $\left.{ }^{-1}\right)$ from JET to ITER, considering a 4 times larger surface area in ITER and a 50\% tritium content in the plasma, one arrives at a permanent retention of $0.5 \mathrm{gT}$ within just one $400 \mathrm{~s} \mathrm{D:T}$ pulse in ITER. The tritium inventory limit in ITER may as such be reached within the first few years of ITER D:T operation if no conditioning techniques are applied [7].

This contribution provides an overview of recent wall conditioning results in view of devices with superconducting coils. Section 2 discusses conditioning that requires deenergised magnetic field coils: baking, glow discharge conditioning (GDC) and the application of wall coatings through GDC-plasma. Section 3 discusses conditioning techniques that operate in the presence of the toroidal magnetic field $\left(B_{T}\right)$, namely radio frequency $(\mathrm{RF})$ conditioning without plasma current, both in the ion cyclotron (IC-) and electron cyclotron range of frequencies (ECRF) and diverted conditioning plasmas with nested magnetic flux surfaces. The application of wall coatings via RF plasmas or diverted plasmas, sometimes referred to as "real-time conditioning", is commented throughout the text. Section 4 translates the presented results into a possible strategy to mitigate the tritium inventory build-up in ITER based on discharge conditioning with $B_{T}$.

\section{Conditioning without $B_{T}$}

\subsection{Baking}

Baking is a necessary though lengthy procedure (order of days) applied after machine venting and in-vessel interventions to remove adsorbents such as water and higher hydrocarbons through thermal desorption. The W7-X vessel is baked for 7 days at $150{ }^{\circ} \mathrm{C}$ degrees where after plasma operation foresees active cooling of the plasma facing components (PFC) to $\sim 28^{\circ} \mathrm{C}$ [8]. JT-60SA foresees baking of the divertor and main wall at $200^{\circ} \mathrm{C}$ [9] while the stabilising 
plates may be heated up to $300^{\circ} \mathrm{C}$. The temperature of the vacuum vessel in plasma operation will be kept at $\sim 50^{\circ} \mathrm{C}[10]$. ITER foresees baking of its first wall and divertor cassettes at $240^{\circ} \mathrm{C}$. The divertor can be heated up further to $350^{\circ} \mathrm{C}$ by circulating hot gas in its cooling channels. During plasma operations the PFC will be actively cooled by water with inlet temperature of $70^{\circ} \mathrm{C}$ [2].

The mobility of hydrogen isotopes that are retained in the plasma facing materials increases as well with increased temperature, enhancing their release to the vacuum chamber. Baking in ITER is therefore an important part of the strategy to recover tritium from the vessel, notably the tritium that, similar to the JET-ILW experience [11], will be stored in codeposited beryllium layers at the divertor baffles. The feasible bake frequency and temperature in ITER seems however too low for effective tritium depletion from thick beryllium codeposits [12].

The outgassing pressure at constant surface temperature follows typically a $t^{-0.7}$ time dependency. The power law originates from processes such as thermal de-trapping of particles at trapping site concentrations in the PFC, diffusion of those particles through the material bulk and their recombination to volatile molecules at the surface. The dependency makes that the relative changes in the neutral pressure, $p$, scale inversely proportional to the elapsed time, $\dot{p} / p \propto t^{-1}$, unlike for an exponential decay where $\dot{p} / p=$ cst. Thus, with longer baking time it becomes increasingly difficult to recover molecules from the vessel with outgassing following a power law [8]. Significant removal gains can however be made by extending short conditioning procedures as shown in section 3.2 and 3.3.

\subsection{Glow Discharge Conditioning}

Superconducting devices apply GDC to (i) further deplete contamination layers on the wall surfaces after baking by reducing metal oxides or hydrogenation of carbon-based surfaces [1], (ii) to reset the wall conditions between operation cycles when the superconducting coils are de-energised [13] and (iii) to contribute to tritium-recovery from the ITER PFC [2]. GDC is also used to apply homogeneous low-Z wall coatings (see 2.3).

GDC relies on a hollow cathode discharge in a noble or reactive gas [14]. The to-be-conditioned wall surfaces are grounded and represent the discharge cathode. An excitation source powers multiple anodes that are distributed in the torus. W7-X, JT-60SA and ITER foresee the use of direct current. The anodes, designed for stable discharge operation at pressures of about $2-5 \times 10^{-3}$ mbar, have typically 3 orders of magnitude smaller surface area compared to the cathode.

Secondary electron emission at the cathode sustains the weakly ionized low-temperature GDC plasma (electron temperature $T_{e}<10 \mathrm{eV}$, electron density $n_{e}=10^{16} \mathrm{~m}^{-3}$ ). The electrons are emitted upon ion impact and accelerate to the plasma in the cathode sheath (200-400V) [15]. The ions, produced by electron impact ionization of the neutral gas, accelerate towards the surfaces in the same cathode fall where they release adsorbents through physical or chemically assisted sputtering. The ion current therefore determines the release rate of adsorbents from the surface. The current density is proportional to the plasma density that decays with increasing distance from the anode. The discharge homogeneity can be improved significantly by placing multiple anodes and optimising the working pressure [16].

ITER aims at a glow current of $0.2 \mathrm{~A} / \mathrm{m}^{2}$ for its $1000 \mathrm{~m}^{2}$ wall using 7 anodes. 2D multi-fluid modelling, approximating the ITER volume by concentric spheres, shows reasonably homogenous density, temperature and plasma potential already by using two anodes, delivering approximately 0.03 $\mathrm{A} / \mathrm{m}^{2}$ per anode [14]. W7-X with a total surface area of 200 $\mathrm{m}^{2}$ operates GDC at 10-15 A using 10 anodes [17].

The efficiency determining factors for GDC, and discharge conditioning in general, are represented in the neutral pressure balance equations. An example for a helium (He) discharge applied to remove hydrogen $(\mathrm{H})$ from the $\mathrm{PFC}$ is given below. W7-X routinely used such procedure between operational days throughout its first two operation campaigns [13].

$$
\begin{aligned}
\dot{p}_{H e} \approx Q_{H e} & -p_{H e} \frac{S_{H e}}{V}- \\
\dot{p}_{H_{2}} \approx-p_{H_{2}} \frac{S_{H_{2}}}{V} & +c(t) Y_{H e^{+}} p_{H e} k_{H e}^{i} n_{e} \\
& -\left(1-R_{H_{2}^{+}}\right) p_{H_{2}} k_{H_{2}}^{i} n_{e}
\end{aligned}
$$

The main species striking the wall are single ionised helium ions and $\mathrm{H}_{2}{ }^{+}$-ions stemming from direct ionization of wall released $\mathrm{H}_{2}$ [18]. Their flux is proportional to the gas pressure $\left(p_{H e}\right.$ and $\left.p_{H_{2}}\right)$, the ionisation rate $\left(k_{H e}^{i}\right.$ and $\left.k_{H_{2}}^{i}\right)$ and the electron density $\left(n_{e}\right)$. The helium flux, $p_{H e} k_{H e}^{i} n_{e}$, mobilises the hydrogen atoms in the PFC and hence appears both in the helium and hydrogen pressure balance. A steady helium pressure is obtained when the external gas flow $Q_{H e}$ is balanced by (i) vacuum pumping, with $S_{H e}$ the effective pumping speed for helium in the vessel and $V$ the vessel volume, and (ii) the retention rate of helium in the PFC, with $R_{H e}+$ the recycling coefficient. Similarly, a slowly varying hydrogen pressure will develop where wall release, dependent on the time varying hydrogen concentration in the PFC, $c(t)$, and the maximum $\mathrm{H}_{2}$ removal yield per impinging helium ion, $Y_{\mathrm{He}^{+}}$, is balanced by (i) vacuum pumping and (ii) redeposition of hydrogen on/in the PFC. The removal yield (detrapping, diffusion, desorption) and recycling coefficients (implantation) are material dependent.

Maximising removal $\left(p_{\mathrm{H}_{2}} \frac{S_{\mathrm{H}_{2}}}{\mathrm{~V}}\right)$ while minimising retention or re-deposition of both the injected and wall released gas (1$\mathrm{R}$ ) is achieved by pulsed discharge conditioning as shown for hydrogen IC conditioning discharges in TORE SUPRA [19]. Pumping (and outgassing) continues between pulses $\left(n_{e}=0\right.$ in above equations). Retention on the other hand is 

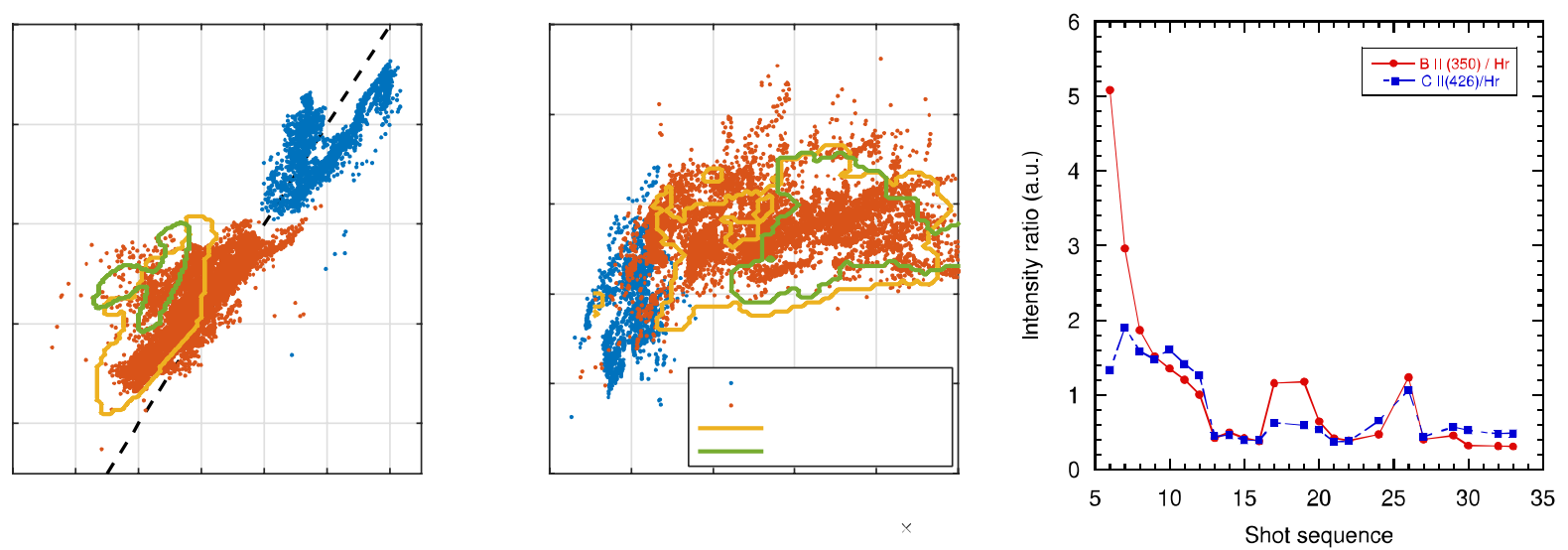

Figure 1 : W7-X data samples from all discharges in standard configuration (EXM) of the second divertor campaign OP1.2b, separated by 3 boronizations. Left: Oxygen and carbon radiation from passive spectroscopy viewing the W7-X divertor. Centre: line integrated plasma density and confinement time. Right: Peak value of boron and carbon photon flux from overview spectrometer looking at the divertor target [28] in $\mathrm{H}$ discharges after the 1st boronization in W 7-X.

proportional to the plasma duration $\left(n_{e} \neq 0\right)$. Similar discharge duty cycle optimization was made possible for GDC in ASDEX Upgrade. The full tungsten device reported an increase of the helium content in plasma discharges following He-GDC with thereby reduced plasma performance [20]. The glow discharge system of ASDEX Upgrade, which includes a starting device on each anode, was therefore upgraded to allow the fast ignition of the glow at the working pressure. This omits the need for a tenfold pressure increase to obtain Paschen breakdown. Comparing different discharge duty cycles for GDC procedures with 5 minutes duration, it is found that 10 -second-long discharges followed by $50 \mathrm{~s}$ for pumping are optimal. Retention of helium is reduced by $83.3 \%$ while removing still $68.7 \%$ of the hydrogen compared to continuous GDC operation [20].

The applicability of GDC for T-recovery in ITER is assessed by considering 5 operation days with a modest number of 10 pulses per day of $400 \mathrm{~s}$ each operated in JET. The worst case estimation for such an operation week is that up to $3 \times 10^{24} \mathrm{H}$ isotopes may be retained in permanent deposits and by implantation. Isotopic exchange experiments by $\mathrm{H}_{2}-$ GDC in JET-ILW [21] evidenced the removal of $9.3 \times 10^{22} \mathrm{D}$ atoms from the first wall. This estimate limits the interest of GDC for T-recovery in ITER as it would require de-energizing the TF coils more frequently than once a week.

\subsection{Boronization through GDC}

Applying low atomic number (low-Z) wall coatings, either boron (B), silicon or lithium, onto the PFC is very effective for suppressing metal impurities and oxygen gettering. In addition, a strong wall pumping capability and hence low hydrogen recycling conditions can be achieved with such coating [1]. Both W7-X, with carbon-based heat flux components and a metallic first wall, and JT-60SA with carbon-based PFC foresee the use of boron [17], [22]. Full tungsten devices ASDEX Upgrade and WEST use also regular boronizations throughout their operations campaigns to reduce the influx of $\mathrm{W}$ and intrinsic impurities from the main chamber PFC [23], [24]. ITER is equiped with a beryllium main chamber wall and does, therefore, not foresee the use of wall coatings. Firstly, the ITER-like-wall in JET has demonstrated 10 times lower initial oxygen plasma content compared to the earlier operation phases with carbon-based PFC due to oxygen gettering on the beryllium first wall [25]. Secondly, introducing wall coating material in ITER leads to the build-up of tritiated low-Z films in the vacuum vessel which is incompatible with the strict tritium inventory limit.

The boronization of the wall is typically applied through a glow discharge in a mixture of helium and diborane $\left(\mathrm{B}_{2} \mathrm{H}_{6}\right.$ or $\mathrm{B}_{2} \mathrm{D}_{6}$ at $10 \%$ ), followed by a short glow in pure helium to crack the remaining diborane molecules and to desature the surfaces from hydrogen isotopes. The experimental procedure is known to produce high quality homogeneous thin films [1]. The thickness of the layer, typically up to $100 \mathrm{~nm}$, is estimated by assuming that all injected boron atoms are contained in the amorphous layer [26], with good agreement to post mortem analysis [27]. The coating is temporary. The surface coverage of the coating is challenged by erosion and deposition processes. At plasma-exposed areas, the boron layer can be completely eroded with time. The typical erosion rate at the strike lines on the divertor target is estimated at $0.25 \mathrm{~nm} / \mathrm{s}$. Figure 1 (right) shows that at the W7-X divertor strike lines, the boron radiation [28] reduces quickly in the first pulses after boronization, each with $7.5 \mathrm{~s}$ duration, 2-4 MW of electron cyclotron resonance heating $(\mathrm{ECRH})$ and a plasma density of $2 \times 10^{19} \mathrm{~m}^{-3}$. The erosion rate at the main wall is one order of magnitude lower based on tokamak experience [27], which, so far, appears different in a stellarator as discussed below.

The boronization effect in the second divertor campaign $\mathrm{OP} 1.2 \mathrm{~b}$ in stellarator W7-X is illustrated by Figure 1 and further reported in [29]. Boronization reduced the oxygen 
influx at the divertor by $8 \mathrm{x}$ (left). Carbon erosion, as a result, dropped significantly with $10 x$ lower fluxes at the divertor (left) and supressed $\mathrm{CO}$ outgassing pressures in the mass spectrometer after the discharge [30]. With less intrinsic impurities, the operational space increased by a factor 4 for density and 2 for confinement time (Fig 1, centre). Subsequent boronizations further reduced the oxygen content while, in contrast to the experience in tokamaks with carbon-based PFC [1], so far, no degradation back towards pre-boronization conditions is observed (Fig. 1 left and centre, further discussed in [31]). Unlike in stellarator W7-X, a tokamak discharge features phases during which the plasma is limited on the main chamber PFC. Local erosion of the boron layer during these limiter phases, namely the burn-through, current ramp-up and current ramp-down phase, is inevitable.

W7-X aims at upto 30 minutes long plasma pulses [32], a significant duration compared to the $\sim 9000 \mathrm{~s}$ of total plasma time during the above discussed Op1.2b campaign. JT-60SA foresees pulses with $100 \mathrm{~s}$ current flat-top duration [33]. Erosion of the main wall coatings between subsequent boronizations may therefore affect the experimental research program at these devices. Boronization through GDC requires de-energised coils and moreover strict safety measures regarding the toxic and explosive diborane gas. Alternative techniques to apply low- $Z$ wall coatings applicable in presence of the magnetic field may therefore be favorable for superconducting long-pulse devices. The layer formation in such techniques is expected to be inhomogeneous due to magnetic field related transport. IC and EC plasma assisted depostion is studied in TEXTOR and TOMAS where, depending on the used precursor gas, the films exhibited high hydrogen contents [34]. Dropping low-Z powder in diverted plasmas is presently researched. Injection of boron powder in $\mathrm{H}$-mode conditioning plasmas in ASDEX Upgrade allowed the suppression of edge localized modes in the subsequent plasma by using use magnetic perturbations. These plasma experiments normally rely on standard boronization [35]. Beneficial effects of similar real-time conditioning, namely injecting powders into long high performance discharges, is also investigated, where efforts are put in keeping up the plasma purity and minimising the total powder throughput to avoid accumulation of thick deposits in long pulses [36].

\section{Conditioning with $\mathbf{B}_{\mathbf{T}}$}

\subsection{Conditioning by ECRH plasma}

Conditioning by ECRH plasma relies on a currentless discharge produced by localised power absorption at the fundamental EC resonance or its second harmonic. The location and size of the plasma-wetted area is determined by the shape of the confining magnetic field. Figure 2 illustrates thereto the key difference between ECRH plasma in a stellarator (left) and in a tokamak (right), the first with and the

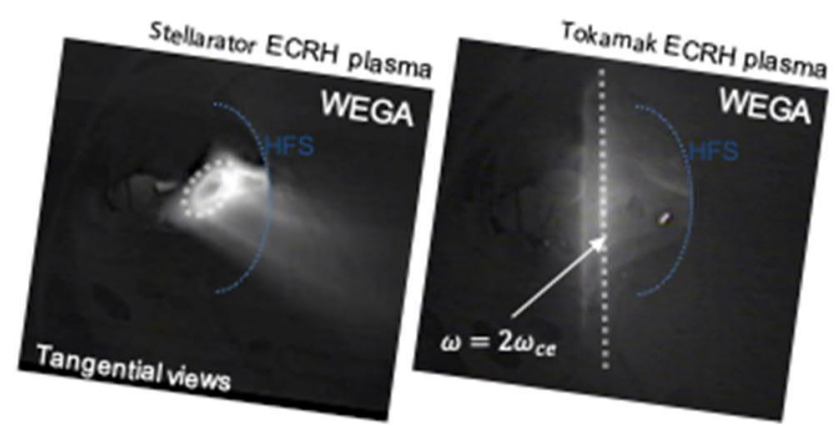

Figure 2 : He-ECRH plasma on WEGA at 28GHz (X2), $1.3 \times 10^{-4}$ mbar and $7.5 \mathrm{~kW}$ launched power. Left : stellarator vacuum field of $450 \mathrm{mT}$ on axis with $\iota / 2 \pi=0.4$. Right : tokamak vacuum field of $500 \mathrm{mT}$ on axis with $\iota / 2 \pi=0$.

second without nested flux surfaces as visible from the shape of the plasma drift surfaces. ECRH plasma in a stellarator is fully ionised $\left(T_{e}>100 \mathrm{eV}\right)$ with density above $n_{e}>10^{19} \mathrm{~m}^{-}$ ${ }^{3}$ with strong surface interaction at the divertor strike lines. The diverted plasma distinguishes from normal operation by their optimization for removal rather than, for example, stored energy. Such optimisations target the ECRH duty cycle or strike line positions on the target plates [30]. Section 3.1.1 discusses results for $\mathrm{W} 7-\mathrm{X}$. In contrast, due to poor confinement, relatively low temperature $\left(T_{e}<100 \mathrm{eV}\right)$ and only partially ionised plasma is obtained in a tokamak. The plasma density strongly peaks at the resonance layer with values being close or below $n_{e} \leq 10^{19} \mathrm{~m}^{-3}$. Section 3.1.2 discusses results of TCV in view of JT-60SA operation.

Safe ECRH plasma operation requires minimising the EC stray radiation, i.e. minimising the possible absorption of EC energy on in-vessel components. Hereto (i) the plasma breakdown phase, without measurable density and hence negligible EC absorption by plasma, needs to be short and (ii) more importantly the absorption during the longer plasma phase needs to be high. The breakdown time depends on the gas and its pressure, the ECRH power, polarisation and launch angle, and the distance of the EC resonance to the magnetic axis in a stellarator or the applied poloidal field in a tokamak [37]-[40]. Plasma production in ordinary EC polarisation mode is less efficient and relies on depolarisation of the bundle to extraordinary (X-) mode upon reflection on the vessel walls.

The plasma breakdown time is typically below $20 \mathrm{~ms}$. In $\mathrm{W} 7-\mathrm{X}$ it is followed by a phase of similar duration where the plasma expands radially, becomes fully ionised at the EC resonance and reaches full absorption with minimal stray radiation in the steady plasma phase that follows [41]. Absorption in X-mode at the second EC harmonic (X2), proportional to $n_{e} T_{e}$, is typically below $50 \%$ in a tokamak ECRH plasma [42]. Full single pass absorption is however possible at fundamental X1-mode. JT-60SA foresees thereto ECRH power at $82 \mathrm{GHz}(1 \mathrm{~s})$ for wall conditioning and startup assistance [43]. 
An ECRH conditioning scenario without full ionization is tested at $\mathrm{W} 7-\mathrm{X}$ via fast repetition of ultra-short pulses $(3 \mathrm{~ms})$ aiming at a large uniform atomic hydrogen flux to the PFC [44].

\subsubsection{Divertor conditioning by ECRH plasma at W 7-X}

W7-X used pulsed He-ECRH plasmas to desaturate the graphite divertor targets from hydrogen and achieve stable low-density operation with boronized walls. Figure 3a shows that the plasma density in reference hydrogen discharges decreased by a factor $\sim 2$, approaching the requested set value, by applying 19 helium pulses of $3 \mathrm{~s}$ duration and $2.1 \mathrm{MW}$ of ECRH power. The pulses were launched in two separate sets with a $35 \mathrm{~s}$ pulse interval. The density decreased from pulse to pulse due to a decreasing contribution of wall fuelling, showing no signs of saturation yet.

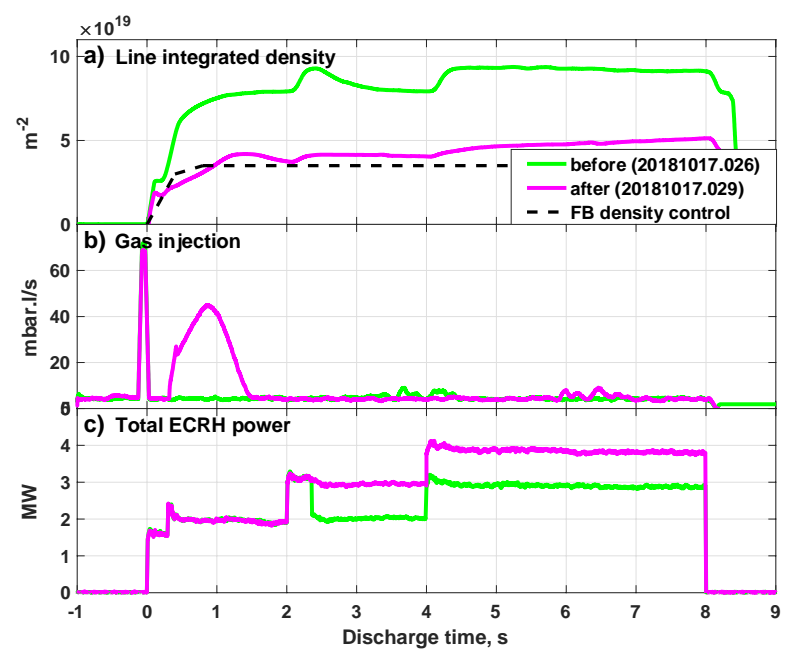

Figure 3 : Reference discharges on W7-X before (20181017.026) and after (20181017.029) application of He-ECRH conditioning. a) line integrated density and density feedback control, b) total gas injection, c) ECRH input power.

In contrast to the strong interaction in the divertor, ECRH plasma in $\mathrm{W} 7-\mathrm{X}$ reveals weak interaction with the main wall. This is evidenced by the single envelope curve for $\mathrm{CO}$ outgassing in about 16 hours of $\mathrm{H}_{2}$-GDC performed throughout the first divertor campaign Op1.2a, ran without boronization [8]. The curve remains unaffected by ECRH plasma operation, including normal operation and conditioning pulses, with 3775 s of total duration in 1248 pulses in Op1.2a. Hydrogen uptake or retention in co-deposits on the main wall therefore cannot be resolved by ECRH conditioning on a stellarator. Indications of this are found in the gas balance analysis of helium ECRH conditioning pulses in Op1.2a. The diverted ECRH plasmas only partially offset the $\mathrm{H}$ inventory build-up throughout an operation day [8]. Instead, He-GDC was used to recover hydrogen from the main wall and regain low recycling conditions in the first pulses of the next operation day, until the first boronization in the Op1.2b campaign.

The first experimental campaign at W7-X, OP1.1, in limiter configuration allowed studying the applicability of limiter (ECRH) discharges for initial wall conditioning, replacing GDC applied after first wall baking. This experience is instructive for tokamak commissioning operations as ohmic plasma is similarly limited on surfaces in the main chamber during the start-up phase. The usage of GDC, applied in helium only, was minimised throughout OP1.1 to avoid sputtering and migration from unprotected metallic surfaces. Hydrogen recycling dominated the fuelling of the discharges throughout OP1.1 while strong CO outgassing was found at the start of the campaign. As the pulse duration of the limiter discharges was constrained by the outgassing itself, it proved to be time consuming to obtain lasting low outgassing levels by limiter plasmas. The wall conditions, defined by the injectable energy in the discharge until a radiative collapse occurs, improved along a power law envelope curve in which relative progress slows down with increasing conditioning duration. The limiter campaign achieved 311 cumulated discharge seconds. It is concluded that the limiter discharges are not ideally suited for the purpose of initial conditioning, neither in helium, nor in hydrogen [13].

\subsubsection{Electron Cyclotron Wall Conditioning in TCV}

JT-60SA relies on Electron Cyclotron Wall Conditioning (ECWC) as sole conditioning method in the presence of the toroidal field to allow plasma start-up [43]. Helium ECWC experiments are performed at TCV in $\mathrm{X} 2$ mode at $82.7 \mathrm{GHz}$ in support of JT-60SA operation. Discharge parameters in the experiment in TCV were tuned in order (i) to minimize the absorption of stray radiation by in-vessel components by minimizing the time for ECRH plasma breakdown, and maximizing the absorption of ECRH power over the duration of the discharge, (ii) to improve the discharge homogeneity, by extending the discharge vertically and radially, and wall coverage, in particular of inboard surfaces where JT-60SA plasmas will be initiated [43], and (iii) to improve the efficiency of He-ECWC to deplete carbon-based PFC from fuel. For all above purposes, the application of a vertical field component of about $0.5 \%$ of the toroidal field is found to be critical [40]. It reduces the breakdown time and increases the achievable density by compensating the vertical $B \times \nabla B$ drift by a vertical pitch angle [37], [45]. Fuel removal, quantified by penning gauge spectroscopy, increased by a factor 5 upon reaching these higher densities. The inboard can be reached by moving the resonance position closer to the high field side, favouring operation at $82 \mathrm{GHz}$ at $2.25 \mathrm{~T}$ over the 110 or $138 \mathrm{GHz}$ in JT-60SA, with adds to the advantage of good absorption at the fundamental EC resonance. Applying a quadrupole shaped poloidal field combining a radial and 
vertical field component allowed measurable ion currents at the TCV inner wall with on axis X2 heating [40].

The recently developed 1-dimensional reaction-diffusionconvection code Tomator-1D simulates plasma production by RF waves inside a tokamak using the Braginskii continuity and heat balance equations. It is developed to complement experimental data of TCV providing insight to e.g. ECRH absorption and transport properties as a function of the applied vertical magnetic field component. The plasma simulator describes the evolution of the radial density and temperature profiles from a transient to a steady state conditions for the 9 main species in partially ionised hydrogen-helium plasma mixtures (e, $\mathrm{He}, \mathrm{He}^{+}, \mathrm{He}^{++}, \mathrm{H}_{2}, \mathrm{H}_{2}{ }^{+}, \mathrm{H}_{3}{ }^{+}, \mathrm{H}, \mathrm{H}^{+}$), including the particle balance for carbon impurity traces (CI to $\mathrm{CV}$ ). The ECRH power couples to the electrons at the grid point where the RF frequency corresponds to the second harmonic gyration frequency $\omega=2 \omega_{c, e}$. Collision rates are included selfconsistently as described in [46] assuming Maxwellian energy distributions. The model includes parallel and perpendicular transport losses with respect to the field lines: (i) parallel in vertical direction on the top and the bottom of the vessel, (ii) parallel in toroidal direction on 6 poloidal limiters, both at the high and low field side, and (iii) perpendicular in radial direction due to diffusion and convection.

Figure 4 shows experimental density profiles from a pulseto-pulse vertical field scan in X2-ECRH plasma at TCV. The resonance layer locates at $89.4 \mathrm{~cm}$. Tomator-1D simulations, given in solid lines, reproduce the experimental data and predict Bohm like diffusion transport, convection losses of order $10-100 \mathrm{~m} / \mathrm{s}$ and an ECRH absorption scaling that is consistent with the $P_{a b s} / P_{i n} \propto n_{e} T_{e}$ dependency predicted by quasi-optical beam tracing simulations with GRAY [47]. The simulated helium ion fluxes at the wall for the discharge with vertical field of $0.5 \%$ are about 3 orders of magnitude higher at the low field side compared to the high field side. Likewise, the parallel losses on limiters, both at high field side $\left(\sim 10^{14}\right.$ $\left.\mathrm{cm}^{-2} \mathrm{~s}^{-1}\right)$ and low field side $\left(\sim 10^{17} \mathrm{~cm}^{-2} \mathrm{~s}^{-1}\right)$, are 3 orders higher than the perpendicular helium ion flux onto the main wall which is, in the simulation, recessed by $2.4 \mathrm{~cm}$. Finally, in these helium plasmas aimed at hydrogen removal from the wall, a hydrogen atom flux towards the wall of order $10^{16} \mathrm{~cm}^{-}$ ${ }^{2} \mathrm{~S}^{-1}$ is predicted, both at the high and low field side. The helium and hydrogen neutral pressure in the simulations are fixed to the experimental values of $1.68 \times 10^{-4} \mathrm{mbar}$ for helium and 4.3 $\times 10^{-5}$ mbar for deuterium, measured by penning gauge spectroscopy during the steady plasma phase.

To arrive at predictive capabilities for larger devices such as JT-60SA it is necessary to understand how the transport processes depend on the vessel dimensions via a multimachine study. Continuation of the modelling efforts for TCV remains needed as the present model seems to underestimate the experimental temperatures by a factor of 2 .

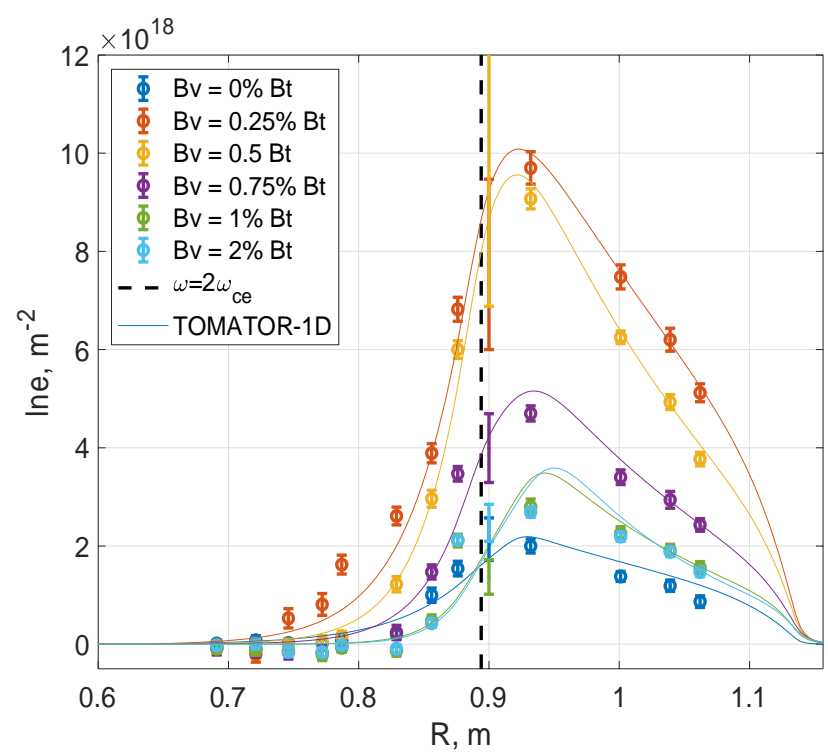

Figure 4 : Effect of a vertical field on the X2-ECRH plasma density on TCV (\#57327-57335). The launched ECRH power was 400kW at $82.7 \mathrm{GHz}$ and $1.5 \mathrm{~T}$ with toroidal and poloidal injection angle of $19.3^{\circ}$ and $7.0^{\circ}$ respectively. The data points stand for time averaged experimental line integrated densities and space and time averaged Thomson density at $R=0.9 \mathrm{~m}$. Simulated profiles by Tomator-1D are given by solid lines.

\subsection{Ion Cyclotron Wall Conditioning in tokamak}

Ion Cyclotron Wall Conditioning (ICWC) was originally developed for stellarators [48] and later successfully applied in tokamaks [49], [50]. Numerous experiments evidenced the effectiveness of ICWC in tokamaks. Experiments demonstrated (i) recovery of sustained ohmic breakdown and density control after disruptions [51] and after severe impurity exposure [52], (ii) full change-over of the isotopic ratio of the JET ITER like wall [53] and (iii) efficient depletion of the tungsten ASDEX Upgrade wall from deuterium by He-ICWC in comparison with $\mathrm{H}$-mode plasmas in helium [54]. The ITER research plan considers ICWC as the preferred RF conditioning technique for the conditioning of the first wall surfaces in presence of the toroidal magnetic field [2]. ICWC is included in the functional requirements of its ion cyclotron resonance heating and current drive system (ICRH\&CD) [55].

\subsubsection{ICRF plasma production}

The present description of the ICRF discharge for wall conditioning distinguishes the breakdown phase and the steady wave phase. ICRF plasma breakdown is experimentally defined as the moment of first appearance of antenna loading which results in an RF voltage drop on the antenna and coincides with the appearance of first plasma radiation. This radiation forms initially a toroidally homogeneous plasma column located close to the antenna straps where the vacuum field is strongest [56]. ICRF plasma breakdown in the tokamak vacuum magnetic field results from 

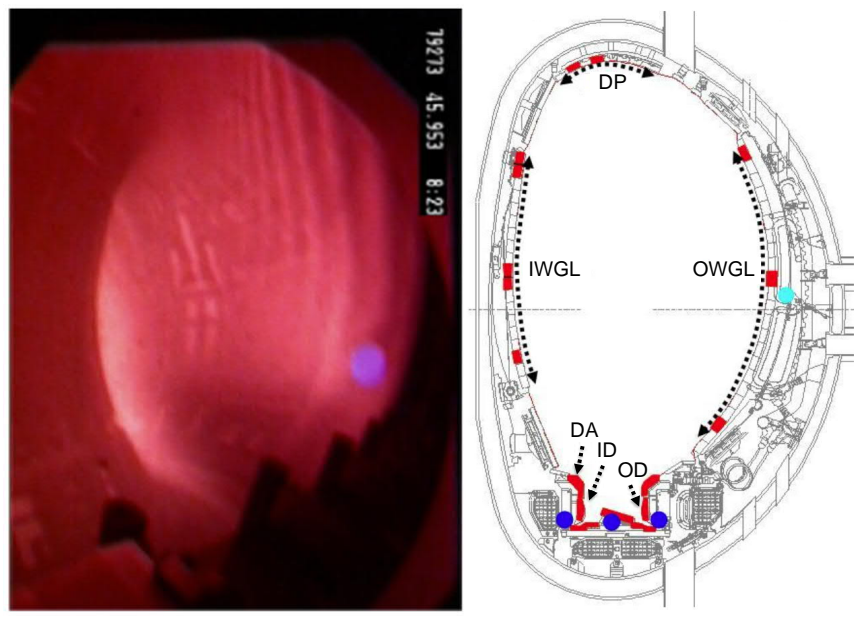

Figure 5 : Left: Vertical and radial extension of JET ICWC discharge (JPN79273, $\mathrm{D}_{2}$-ICW C, 25M Hz, 3.3T, $P_{R F, c}=250 \mathrm{~kW}, p=2 \times 10^{-5}$ mbar, barrel shaped $B_{P}=30 \mathrm{mT}$,), image adapted from [51]. Right: Poloidal cross section of the JET vessel indicating: Outer Poloidal Limiters (OPL), Inner Wall Guard Limiters (IWGL), Upper Dump plates (DP), Divertor Apron (DA), Inner Divertor (ID) and Outer Divertor (OD), image adapted from [67].

the ionization avalanche by electrons accelerated by the parallel RF electric field $\left(E_{z} \| B_{T}\right)$ in the vicinity of the ICRF antenna. $E_{z}$ is produced electrostatically by the potential difference between the antenna strap and the side parts of the antenna box and inductively through the magnetic flux by the induced voltage difference between the tilted faraday screen rods [57].

The breakdown phase is studied using Particle-in-cell Monte-Carlo collision (PIC-MCC) model Rfdinity-1D [56]. The model, 1D in toroidal direction, follows the motion of electrons and ions in a narrow bundle that passes close to the antenna straps. The charged particles are accelerated by (i) the vacuum parallel electric field component $E_{z, R F}$ and (ii) the plasma-generated electrostatic field $E_{z, P}$ obtained from Poisson's equation. The included electron collisions with background neutrals determine the occurrence of an electron multiplication avalanche. Rfdinity-1D reproduces TEXTOR [58], ASDEX Upgrade [59] and IShTAR experiments [60] and predicts successful plasma production with the ICRF antenna in ITER [61].

Rfdinity-1D identified moreover distinct phases in the density build-up from vacuum to the slow wave cut-off $\left(\sim 10^{13}\right.$ $\left.\mathrm{m}^{-3}\right)$, marked by the strength of the plasma-generated field compared to the vacuum parallel electric field. When $\left|E_{z, P}\right| \ll$ $\left|E_{z, R F}\right|$, a steady bi-Maxwellian electron energy distribution is formed with a constant ionisation reaction rate. At a density of $\sim 10^{11} \mathrm{~m}^{-3}$, with $\left|E_{z, P}\right|<\left|E_{z, R F}\right|$, the distribution develops a single power law tail which increases the ionisation rate. A dramatic increase of the latter follows when $\left|E_{z, P}\right| \approx\left|E_{z, R F}\right|$ at $\sim 10^{12} \mathrm{~m}^{-3}$, which is interpreted as the numerical breakdown moment. The ions and electrons in this final simulated phase both have a Kappa distribution, typical for non-thermalized plasma with strong electric fields. The toroidal propagation of Langmuir charge density waves is as well observed. These waves become evanescent near $\omega=\omega_{p, e}$ i.e. when the Slow Wave starts propagating radially. At this moment the plasma wave phase is said to start throughout which the plasma spreads poloidally to uniformly fill the vacuum vessel (Figure 5). The model Tomator-1D (see section 3.1.2) coupled to the KIPT ICRF coupling module [62] is developed to study the wave phase of ICWC discharges.

ICWC in tokamaks makes use of the standard poloidal strap ICRH\&CD antennas that are designed to couple the Fast Wave to dense $\left(>10^{19} \mathrm{~m}^{-3}\right)$ plasma. Decreasing the cut-off density for fast wave propagation improves RF coupling and discharge homogeneity in the partially ionised ICWC discharges. This can be achieved by operating at high cyclotron harmonics, with strongly reduced toroidal magnetic field values $\left(\omega>\omega_{c, i}\right)$, or by reducing the antenna spectrum towards $k_{z}=0$, i.e. by using a single strap or monopole phasing of multiple straps [57]. JET evidenced that ICRF plasma production is robust and works at any heating scenario using the $\mathrm{A} 2$ antennas in monopole at $25 \mathrm{MHz}$ in

- $\mathrm{D}_{2}$-ICWC at $\omega=\omega_{c, H^{+}}$corresponding to the ITER full field scenario at $5.3 \mathrm{~T}$ and $40 \mathrm{MHz}$, and at $\omega=2 \omega_{c, H^{+}}$

- $\mathrm{H}_{2}$-ICWC at $\omega=[0.5-10] \omega_{c, D^{+}}$including $\omega=\omega_{c, D^{+}}$ corresponding to the ITER half field scenario at $2.65 \mathrm{~T}$ and $40 \mathrm{MHz}$.

\subsubsection{Fuel recovery by ICWC}

Fuel recovery experiments to study the $\mathrm{T}$ removal capability of ICWC have been performed in JET-ILW. These isotope exchange experiments aim at replacing hydrogen isotopes from the near surface $(<100 \mathrm{~nm})$ stored by implantation or in deposits. Figure 6 shows cumulated removal tendencies for 3 ICWC experiments in JET-ILW. Plotted as function of the cumulated coupled ICRF energy, all experiments follow a similar power law envelope curve (dashed lines) with exponent $E^{0.5}$ for the total removal. The dependency indicates that significantly more gas can be removed still by extending the conditioning procedure. The trend lines show indeed no saturation yet. The maximum amount of isotopes than can be removed is called the assessible reservoir and depends on the heating scenario as visible by the discontinuity in the yellow data points at $12 \mathrm{MJ}$. The magnetic field was here lowered from 3.3T to $1.65 \mathrm{~T}$ to allow for a longer magnetic flat top and hence longer discharges. As the pulse repetition rate was limited to 1 discharge every 15-20 minutes, this field reduction allowed achieving a longer total discharge time in the experimental session. As such, the maximum evidenced removal from the JET-ILW by $\sim 630 \mathrm{~s}$ of $\mathrm{D}_{2}$-ICWC plasma (yellow data points in figure 6) is $8.6 \times 10^{22}$ isotopes and was measured by combining volumetric analysis and gas chromatography. Net 


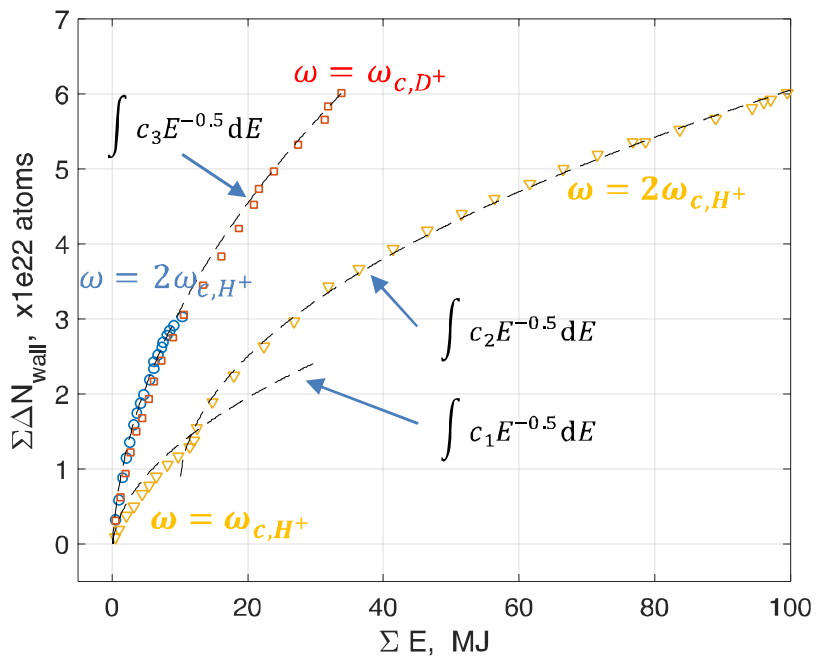

Figure 6 : Removal-integral by mass spectrometry as function of coupled energy-integral for 3 ICWC experiments on the JET-ILW at $25 \mathrm{M} \mathrm{Hz}, 100-300 \mathrm{~kW}$ of coupled power, discharge pressure of $0.5-$ 7.5x10-5mbar. Blue: $\mathrm{D}_{2}-\mathrm{ICWC}$ and 3.3T with 2-8 s discharges. Red: $\mathrm{H}_{2}-\mathrm{ICW} C$ at $25 \mathrm{M} \mathrm{Hz}$ and $1.65 \mathrm{~T}$ with $2-20 \mathrm{~s}$ discharges. Yellow: $\mathrm{D}_{2}-$ ICWC at 3.3T and 1.65T with 5-20 s discharges. Dashed lines: Comparative power law envelope curves.

retention is observed in the experiments. This retention is a consequence of the chosen duration for the separate discharges, up to 20 seconds, and can be mitigated on a superconducting device by optimising the duty cycle (ref. equations in section 2.2). Removal dependencies on coupled power, discharge pressure and plasma density are described in [63].

\subsection{Divertor conditioning by tokamak plasma}

Conditioning by tokamak plasma is attractive as it allows to deposit large particle fluxes and heat on localised surfaces such as the divertor targets. ITER considers the use of deuterium discharges to heat and remove tritium-rich deposits [12]. Removal optimisations via the discharge duty cycle are however not feasible for tokamak plasma as the repetition rate of these discharges is limited by cycling the central solenoid, data collection and systems controls. The permanent retention of accessible fuel released during the conditioning discharge therefore needs to be considered, even more as most of the gas in experiments as discussed below is recovered by outgassing in the post discharge phase.

The key processes governing particle recycling by plasma discharges are identified in [6]. Transport of ionised particles in the plasma scrape of layer determines the dominant areas for interaction between plasma and wall. The interaction processes are (i) implantation of fuel in regions that remain accessible to the recycling process, (ii) codeposition of fuel with eroded wall materials, mostly with beryllium, in areas accessible for re-erosion, and (iii) long term retention in form of implantation or codeposits located in areas inaccessible to the used plasma configuration. These deposits contain moreover a large fraction of impurities which are influencing their properties and retention characteristics [64].

The removal capability of tokamak plasma was studied in JET-ILW by isotopic change-over through 16 consecutive hydrogen discharges after a 13 week long deuterium operation phase (the 2014 experiment as described in [6]). The relative D-concentration from subdivertor penning gauge spectroscopy for each of the H-pulses is given on Fig. 7, left axis, as a function of the total discharge duration. The isotopic ratio from plasma spectroscopy follows the same trend with noticable spatial dependency [65]. The discharge length in the plot is taken to be $25 \mathrm{~s}\left(\mathrm{I}_{\mathrm{p}}>1.25 \mathrm{MA}\right)$ of which $15 \mathrm{~s}$ of diverted plasma with low and high triangularity phases and $10 \mathrm{~s}$ operated in limiter mode. The gas balance of the experiment, including 4.5 hours of outgassing after the last discharge, shows that $1.3 \times 10^{23}$ deuterium atoms could be pumped out of the vessel. The retention rate was $6.2 \times 10^{20}$ isotopes. $\mathrm{s}^{-1}$, which is about 4 times higher than the earlier mentioned worst case rates which may indicate temporal changes of the ITERlike wall. The pulse-by-pulse cumulated removal of deuterium from the vessel, calculated by weighting the total removal to the isotopic ratio, is plotted on the right axis of Figure 7. As for ICWC, the data follows a power law trend line $(N \propto$ $\Sigma \mathrm{t}^{-0.6} \Delta \mathrm{t}$ ) indicating that more deuterium can be removed with a longer procedure. Also, the permanent re-deposition of wall released deuterium is shown, estimated by scaling the measured total retention rate with the plasma isotopic ratio. About $20 \%$ of the wall released isotopes are re-deposited instead of evacuated from the vessel. This amount may be reduced by shortening the limiter discharge phase which may feature strong beryllium erosion from the main chamber limiters.

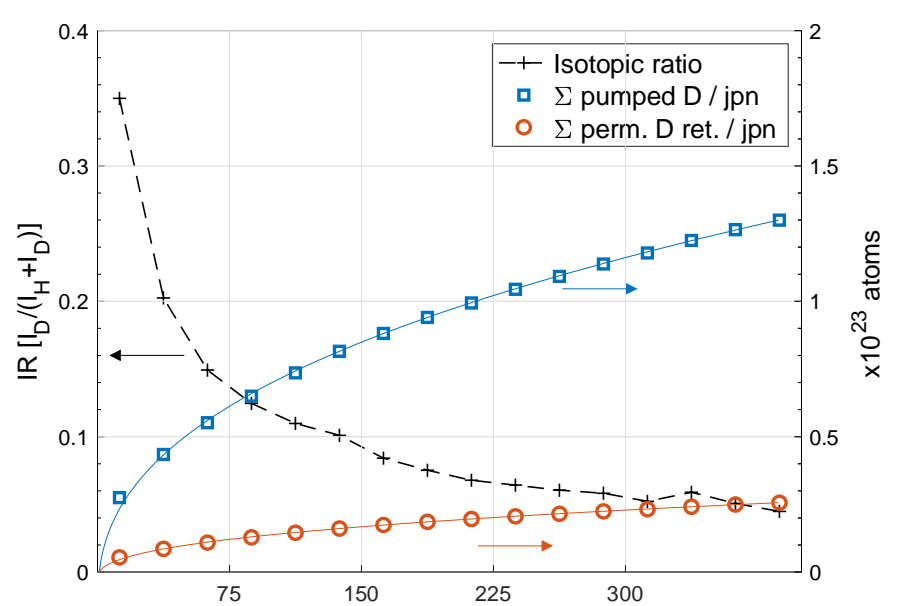

Figure 7 : Isotopic exchange from $\mathrm{D}$ to $\mathrm{H}$ by tokamak plasma on JET-ILW (2014 experiment [6]) with $I_{p}=2.0 \mathrm{MA}, \mathrm{B}_{\mathrm{T}}=2.4 \mathrm{~T},\left(\mathrm{n}_{\mathrm{e}}\right) \approx$ $4.5 \times 10^{19} \mathrm{~m}^{-3}$, constant gas injection of $3.0 \times 10^{21} \mathrm{D} . \mathrm{s}^{-1}$ and $0.5 \mathrm{M} \mathrm{W}$ of ICRH heating in L-mode. Left: Isotopic ratio by subdivertor penning gauge spectroscopy. Right: integral of removal by pumps and redeposition of atoms as function of the total discharge time; blue and red trend line follow envelope curve $\Sigma t^{-0.6} \Delta t$. 


\section{Role of discharge conditioning with $B_{T}$ in T-recovery strategy in ITER}

Table 1 : Summary of the post mortem analysis of retention from JET-ILW 2010-2014 adapted from [11]. See Fig. 5 for locations of listed PFC in JET vacuum vessel.

\begin{tabular}{ll}
\hline JET vessel area & Retention \\
\hline Main chamber beryllium limiters & $22 \%$ \\
Main chamber recessed wall & $10 \%$ \\
Beryllium castellation gaps & $3 \%$ \\
Inner divertor & $44 \%$ \\
Outer divertor & $10 \%$ \\
Remote divertor & $11 \%$ \\
Divertor bulk tungsten & $1 \%$ \\
\hline
\end{tabular}

ITER aims at demonstrating D:T fusion power of $500 \mathrm{MW}$ for a plasma burn duration of $400 \mathrm{~s}$. A $400 \mathrm{~s}$ plasma operated in JET is expected to retain (worst case) $6.0 \times 10^{22}$ isotopes in permanent deposits and by implantation. This is less than the evidenced amounts removed by ICWC $\left(8.6 \times 10^{22}\right.$ isotopes, section 3.2.2) and L-mode plasma $\left(1.3 \times 10^{23}\right.$ isotopes, section 3.3). It is to be noted that the latter removal stems from both the transient and permanent retention areas. The ITER T recovery strategy needs to address, mostly, the permanent retention as the transient retention will be quickly refilled upto $50 \%$ tritium in a subsequent D:T discharge. Areas with permanent retention depend on the used plasma configuration, which varies during typical experimental campaigns. Codeposition patterns from post mortem surface analysis of the first two JET-ILW campaigns differentiate the areas with strong retention [11], summarised in Table 1. The main chamber accounts for about $35 \%$ of the permanent retention on the beryllium limiters, recessed wall and castellation gaps. A remaining 55\% is stored on the divertor surfaces with a most notable accumulation of co-deposits on the divertor baffles. The tabulated values are integrated over limiter phases, leading mostly to co-deposition on beryllium limiters, and divertor phases, leading to co-deposition of beryllium on the tungsten divertor [66]. Conditioning by diverted plasma, with the strike lines moved towards retention dominated areas, is therefore attractive as it allows to mobilise and partially migrate tritium from divertor deposits to areas where it remains accessible to normal operation or further conditioning by ICWC. Areas accessible by ICWC are the outer and inner poloidal limiters and, with supposed reduced fluxes, the upper dump plates and the divertor appron (Fig. 5 [67]).

It remains to be confirmed whether the divertor strike points in ITER can be moved sufficienctly close to erode, or outgas by heating, the deposits from deposition dominated areas on the divertor. If positive, operation in D:T in ITER may foresee, for T-recovery, an extended L-mode phase with only deuterium injection at the end of a D:T discharge followed by pulsed ICWC operation. If negative, then only ICWC can be recommended to mitigate the tritium retention build-up.

\section{Summary}

Fusion devices with superconducting coils, such as W7-X, JT-60SA and ITER, keep these coils energised throughout an experimental day or week. This restricts the use of proven conditioning methods such as baking, GDC and the application of low-Z wall coatings through GDC-plasma. While these techniques stay essential for these devices, except for wall coatings in ITER where the beryllium on the first wall acts as efficient oxygen getterer, new conditioning techniques are needed that work in the presence of the nominal magnetic field. These techniques include RF conditioning without plasma current, both in the ion cyclotron and electron cyclotron range of frequencies, and diverted conditioning plasmas with nested magnetic flux surfaces. Rather than a single best new technique, a combination of techniques may be preferred depending on the conditioning aim and the to-be conditioned surface areas.

$\mathrm{RF}$ conditioning techniques in a tokamak are known as ICWC (foreseen on ITER) and ECWC (foreseen on JT-60SA). Divertor conditioning in a tokamak consist of ohmic plasmas optimised for removal with eventual auxiliary heating. ECRH conditioning plasmas in stellarator W7-X efficiently interact with the divertor area and are therefore more similar to divertor conditioning by tokamak plasma rather than to ECWC in a tokamak. A comparison of ICWC operation in a tokamak and conditioning by IC heated plasmas in W7-X waits for first results with the W7-X ICRH antenna system, currently under construction [68]. The available dedicated experimental comparisons show that ICRF plasma removes more or faster than ECRH plasma, both in tokamak TEXTOR [69] and in stellarator WEGA [70].

Pulsed discharge cleaning allows mitigating the retention of discharge gas or redeposition of wall released species during a conditioning procedure. A pulsed regime can be applied to RF conditioning in tokamaks (ICWC and ECWC), divertor conditioning by ECRH plasma in a stellarator and even for GDC as achieved in ASDEX Upgrade by using a starting device to swiftly initiate the glow at working pressure. Duty cycle optimization in divertor conditioning plasmas in tokamaks is however less straightforward.

ECRH plasma production relies on resonant absorption of RF power at the first or second EC harmonic. The selfconsistent transport model Tomator-1D is used to complement radial plasma profiles from ECWC experiments in tokamak TCV and provides insight regarding the ECRH absorption and the transport properties of these toroidal plasmas without nested flux surfaces. This work is the first step towards predictive capabilities for ECWC operation in larger devices such as JT-60SA and aims at ensuring efficient conditioning as well as safe operation by minimizing possible absorption of EC energy on in-vessel components. ECRH plasma in a stellarator, with nested flux surfaces, features nearly full absorption of EC power by the plasma and strongest plasma 
wall interaction at the divertor strike lines. Helium ECRH discharges are effectively used to desaturate the divertor targets from hydrogen.

ICWC plasma production relies on non-localized (collisional) absorption of ICRF power by electrons and can therefore be operated in a broad range of RF frequencies and toroidal magnetic field values. The plasma breakdown process is well described by PIC-MCC model RFdinity-1D. The model predicts successful plasma production with the ICRH\&CD antenna in ITER. Numerous experiments evidenced the effectiveness of ICWC in tokamaks.

Experiments in JET-ILW assessed T removal by ICWC and L-mode plasmas in view of ITER D:T operation. While Lmode plasma may effectively access the tritium stored in the divertor area, ICWC may be used for removal from the main chamber PFC. The upper estimate for the expected retention in permanent deposits or by implantation in a $400 \mathrm{~s}$ plasma on ITER may be slightly lower than the amounts that can be recovered by ICWC and L-mode plasma, based on the JETILW experience. On the condition that the divertor strike points in ITER can be moved sufficienctly close to the deposition dominated areas on the divertor, operation in D:T in ITER may foresee for T-recovery, an extended L-mode phase with only deuterium injection at the end of a D:T discharge followed by pulsed ICWC operation while preparing the subsequent fusion pulse.

\section{Acknowledgements}

This work has been carried out within the framework of the EUROfusion Consortium and has received funding from the Euratom research and training programme 2014-2018 and 2019-2020 under grant agreement No 633053. The views and opinions expressed herein do not necessarily reflect those of the European Commission.

\section{References}

[1] J. Winter, 'Wall conditioning in fusion devices and its influence on plasma performance', Plasma Phys. Control. Fusion, vol. 38, no. 9, pp. 1503-1542, Sep. 1996.

[2] ITER Organization, 'ITER Research Plan within the Staged Approach', ITR-18-003, Aug. 2018.

[3] G. F. M atthews et al., 'JET ITER-like wall-overview and experimental programme', Phys. Scr., vol. T145, p. 014001, Dec. 2011.

[4] S. Brezinsek et al., 'Fuel retention studies with the ITERLike Wall in JET', Nucl. Fusion, vol. 53, no. 8, p. 083023, Jul. 2013.

[5] K. Heinola et al., 'Fuel retention in JET ITER-Like Wall from post-mortem analysis', Journal of Nuclear Materials, vol. 463, pp. 961-965, Aug. 2015.

[6] T. Loarer et al., 'Plasma isotopic changeover experiments in JET under carbon and ITER-like wall conditions', Nucl. Fusion, vol. 55, no. 4, p. 043021, Mar. 2015.

[7] S. Carpentier et al., 'M odelling of beryllium erosionredeposition on ITER first wall panels', Journal of Nuclear Materials, vol. 415, no. 1, Supplement, pp. S165-S169, Aug. 2011.

[8] T. Wauters et al., 'Wall conditioning throughout the first carbon divertor campaign on Wendelstein 7- $X$ ', Nuclear Materials and Energy, vol. 17, pp. 235-241, Dec. 2018.

[9] P. Barabaschi, Y. Kamada, and H. S. and, 'Progress of the JT-60SA project', Nucl. Fusion, vol. 59, no. 11, p. 112005, Jun. 2019.

[10] S. Ishida, P. Barabaschi, and Y. Kamada, 'Status and prospect of the JT-60SA project', Fusion Engineering and Design, vol. 85, no. 10, pp. 2070-2079, Dec. 2010.

[11] A. Widdowson et al., 'Overview of fuel inventory in JET with the ITER-like wall', Nucl. Fusion, vol. 57, no. 8, p. 086045, Jul. 2017.

[12] G. De Temmerman et al., 'Efficiency of thermal outgassing for tritium retention measurement and removal in ITER', Nuclear M aterials and Energy, vol. 12, pp. 267-272, Aug. 2017.

[13] T. Wauters et al., 'Wall conditioning by ECRH discharges and $\mathrm{He}-\mathrm{GDC}$ in the limiter phase of Wendelstein 7- $X^{\prime}$, Nucl. Fusion, vol. 58, no. 6, p. 066013, Apr. 2018.

[14] D. Kogut, D. Douai, G. Hagelaar, and R. A. Pitts, 'M odelling of tokamak glow discharge cleaning II: comparison with experiment and application to ITER', Plasma Phys. Control. Fusion, vol. 57, no. 2, p. 025009, Dec. 2014.

[15] G. J. M. Hagelaar, D. Kogut, D. Douai, and R. A. Pitts, 'M odelling of tokamak glow discharge cleaning I: physical principles', Plasma Phys. Control. Fusion, vol. 57, no. 2, p. 025008, Dec. 2014.

[16] A. Canton, R. Cavazzana, L. Grando, M. Spolaore, and $M$. Zuin, 'Designing high efficiency glow discharge cleaning systems', Nuclear M aterials and Energy, vol. 19, pp. 468-472, May 2019.

[17] R. Brakel, 'Strategy and optimisation of wall conditioning at the Wendelstein 7-X stellarator', in Indico for IAEA Conferences (Indico), Ahmedabad, India, 2018, vol. IAEA CN-258, p. EX/P8-17.

[18] H. Amemiya et al., 'Characteristics of Cleaning and Carbonizing Plasmas in TEXTOR', Jpn. J. Appl. Phys., vol. 26, no. 9R, p. 1534, Sep. 1987.

[19] T. Wauters et al., 'Isotope exchange experiments on TEXTOR and TORE SUPRA using lon Cyclotron Wall Conditioning and Glow Discharge Conditioning', Journal of Nuclear M aterials, vol. 415, no. 1, Supplement, pp. S1033-S1036, Aug. 2011.

[20] T. Härtl, A. Drenik, M. Kircher, V. Rohde, F. Stelzer, and W. Zeidner, 'Optimization of the ASDEX Upgrade glow 
discharge', Fusion Engineering and Design, vol. 124, pp. 283-286, Nov. 2017.

[21] D. Douai et al., 'Wall conditioning for ITER: Current experimental and modeling activities', Journal of Nuclear M aterials, vol. 463, pp. 150-156, Aug. 2015.

[22] Y. Kamada and G. Giruzzi, 'JT-60SA Research Plan Research Objectives and Strategy', Version 4.0, Sep. 2018.

[23] S. Brezinsek et al., 'Surface modification of He preexposed tungsten samples by He plasma impact in the divertor manipulator of ASDEX Upgrade', Nuclear M aterials and Energy, vol. 12, pp. 575-581, Aug. 2017.

[24] C. Bourdelle, 'Ramping up RF power and increasing pulse length in the full tungsten environment of WEST', in Agenda (Indico), 2019.

[25] S. Brezinsek, 'Plasma-surface interaction in the Be/W environment: Conclusions drawn from the JET-ILW for ITER', Journal of Nuclear M aterials, vol. 463, pp. 11-21, Aug. 2015.

[26] A. Annen, M. Saß, R. Beckmann, and W. Jacob, 'Stability of plasma-deposited amorphous hydrogenated boron films', Thin Solid Films, vol. 300, no. 1, pp. 101-106, May 1997.

[27] V. Rohde, R. Dux, A. Kallenbach, K. Krieger, and R. Neu, 'Wall conditioning in ASDEX Upgrade', Journal of Nuclear M aterials, vol. 363-365, pp. 1369-1374, Jun. 2007.

[28] E. Wang, 'Impurity sources and fluxes in W7-X: from the plasma-facing components to the edge layer', Phys. Scr., vol. PFM C 2019 contribution, 2019.

[29] T. S. Pedersen et al., 'First divertor physics studies in Wendelstein 7-X', Nucl. Fusion, vol. 59, no. 9, p. 096014, Jul. 2019.

[30] A. Goriaev, 'Wall conditioning strategy at the Wendelstein 7 - X stellarator operating with graphite divertor', Phys. Scr., vol. PFM C 2019 paper, no. In review, 2019.

[31] B. Buttenschön, T. Wegner, D. Zhang, M. Kubkowska, A. Czarnecka, and R. Burhenn, 'Reduction of intrinsic impurities by wall boronization in Wendelstein $7-X$ as observed by VUV spectroscopy', presented at the 46th EPS Conference on Plasma Physics, Milan, italy, 2019, vol. P2.1048, p. 1.

[32] T. Klinger et al., 'Towards assembly completion and preparation of experimental campaigns of Wendelstein 7-X in the perspective of a path to a stellarator fusion power plant', Fusion Engineering and Design, vol. 88, no. 6, pp. 461-465, Oct. 2013.

[33] G. Giruzzi, 'Advances in the physics studies for the JT60SA tokamak exploitation and research plan', Plasma Phys. Control. Fusion, 2019.

[34] E. de la Cal and E. Gauthier, 'Review of radio frequency conditioning discharges with magnetic fields in superconducting fusion reactors', Plasma Phys. Control. Fusion, vol. 47, no. 2, pp. 197-218, Jan. 2005.

[35] A. Bortolon et al., 'Real-time wall conditioning by controlled injection of boron and boron nitride powder in full tungsten wall ASDEX Upgrade', Nuclear M aterials and Energy, vol. 19, pp. 384-389, M ay 2019.

[36] A. Bortolon et al., 'Real-time wall conditioning through $B$ powder injection in fusion devices', presented at the 46th EPS Conference on Plasma Physics, M ilan, italy, 2019, vol. P2.1025, p. 1.

[37] M. Preynas, H. P. Laqua, M. Otte, T. Stange, T. Wauters, and D. Aßmus, 'Study of plasma start-up initiated by second harmonic electron cyclotron resonance heating on WEGA experiment', AIP Conference Proceedings, vol. 1580, no. 1, pp. 498-501, Feb. 2014.

[38] Á. Cappa et al., 'Second harmonic ECRH breakdown experiments in the TJ-II stellarator', Nucl. Fusion, vol. 55, no. 4, p. 043018, Mar. 2015.

[39] J. Stober et al., 'ECRH-assisted plasma start-up with toroidally inclined launch: multi-machine comparison and perspectives for ITER', Nucl. Fusion, vol. 51, no. 8, p. 083031, Jul. 2011.

[40] D. Douai et al., 'Development of helium electron cyclotron wall conditioning on TCV', Nucl. Fusion, vol. 58, no. 2, p. 026018, Dec. 2017.

[41] T. Stange et al., 'Advanced electron cyclotron heating and current drive experiments on the stellarator Wendelstein 7-X', EPJ Web Conf., vol. 157, p. 02008, 2017.

[42] M. Fukumoto, T. Nakano, K. Itami, A. Isayama, T. Suzuki, and H. Kubo, 'Efficiency improvement by application of horizontal magnetic fields for second- and fundamental harmonic EC wall conditioning in JT-60U', Nuclear M aterials and Energy, vol. 12, pp. 725-732, Aug. 2017.

[43] G. Giruzzi et al., 'Physics and operation oriented activities in preparation of the JT-60SA tokamak exploitation', Nucl. Fusion, vol. 57, no. 8, p. 085001, Jul. 2017.

[44] V. E. M oiseenko et al., 'A scenario of pulsed ECRH wall conditioning in hydrogen for the Wendelstein 7-X helias', Problems of Atomic Science and Technology, vol. 1, pp. 37-40, 2019.

[45] G. L. Jackson et al., 'Understanding and predicting the dynamics of tokamak discharges during startup and rampdown', Physics of Plasmas, vol. 17, no. 5, p. 056116, May 2010.

[46] T. Wauters et al., 'OD model of magnetized hydrogenhelium wall conditioning plasmas', Plasma Phys. Control. Fusion, vol. 53, no. 12, p. 125003, Oct. 2011.

[47] D. Farina, 'A Quasi-Optical Beam-Tracing Code for Electron Cyclotron Absorption and Current Drive: GRAY', Fusion Science and Technology, vol. 52, no. 2, pp. 154-160, Aug. 2007. 
[48] N. I. Nazarov, V. V. Plyusnin, and T. Y. Ranyuk, 'Cleaning of surfaces by plasma in the Uragan-3 torsatron', Fizika Plazmy, vol. 13, no. 12, pp. 1511-1515, 1987.

[49] H. G. Esser et al., 'ICRF wall conditioning at TEXTOR-94 in the presence of a 2.25 T magnetic field', Journal of Nuclear Materials, vol. 241-243, pp. 861-866, Feb. 1997.

[50] E. Gauthier et al., 'Wall conditioning technique development in Tore Supra with permanent magnetic field by ICRF wave injection', Journal of Nuclear Materials, vol. 241-243, pp. 553-558, Feb. 1997.

[51] D. Douai et al., 'Recent results on Ion Cyclotron Wall Conditioning in mid and large size tokamaks', Journal of Nuclear M aterials, vol. 415, no. 1, Supplement, pp. S1021-S1028, Aug. 2011.

[52] T. Wauters et al., 'Self-consistent application of ion cyclotron wall conditioning for co-deposited layer removal and recovery of tokamak operation on TEXTOR', Nucl. Fusion, vol. 53, no. 12, p. 123001, Nov. 2013.

[53] T. Wauters, 'ICRF Discharge Production for Ion Cyclotron Wall Conditioning on JET', presented at the 25th IAEA Fusion Energy Conference, St. Petersburg, Russia, 2014, vol. Paper EX/P5-21.

[54] A. Hakola et al., 'Plasma-wall interaction studies in the full-W ASDEX upgrade during helium plasma discharges', Nucl. Fusion, vol. 57, no. 6, p. 066015, Apr. 2017.

[55] S. Chiocchio, 'ITER Project Requirements', ITER Organisation, IDM reference 27ZRW8, M ay 2010.

[56] M. Tripský et al., 'A PIC-M CC code RFdinityld for simulation of discharge initiation by ICRF antenna', Nucl. Fusion, vol. 57, no. 12, p. 126043, Oct. 2017.

[57] A. Lyssoivan et al., 'Simulation of ITER full-field ICWC scenario in JET: RF physics aspects', Plasma Phys. Control. Fusion, vol. 54, no. 7, p. 074014, Jun. 2012.

[58] M. Tripský, T. Wauters, A. Lyssoivan, M. Vervier, and K. Crombé, 'M onte Carlo simulation of ICRF discharge initiation at $\omega \mathrm{LHR}<\omega$ ', in Europhysics conference abstracts, 2014, vol. Vol. 38F, p. 4.

[59] M. Tripský et al., 'M onte Carlo simulation of initial breakdown phase for magnetised toroidal ICRF discharges', AIP Conference Proceedings, vol. 1580, no. 1, pp. 334-337, Feb. 2014.

[60] M. Tripský et al., 'Discharge initiation by ICRF antenna in IShTAR', EPJ Web Conf., vol. 157, p. 03056, 2017.

[61] M. Tripský et al., 'M onte Carlo simulation of ICRF discharge initiation in ITER', AIP Conference Proceedings, vol. 1689, no. 1, p. 060009, Dec. 2015.

[62] V. E. M oiseenko, Y. S. Kulyk, T. Wauters, and A. I. Lyssoivan, 'Optimization of self-consistent code for modelling of RF plasma production', Problems of Atomic Science and Technology, vol. 21, no. 1, 2015.
[63] T. Wauters et al., 'Isotope exchange by Ion Cyclotron Wall Conditioning on JET', Journal of Nuclear Materials, vol. 463, pp. 1104-1108, Aug. 2015.

[64] A. Hakola, 'Fuel retention in Be-containing co-deposited layers', Phys. Scr., vol. PFMC_17_2019, 2019.

[65] V. S. Neverov, A. B. Kukushkin, Ū. Kruezi, M. F. Stamp, and $\mathrm{H}$. W. and, 'Determination of isotope ratio in the divertor of JET-ILW by high-resolution $\mathrm{H} \$$ । upalpha\$ spectroscopy: H-D experiment and implications for D-T experiment', Nucl. Fusion, vol. 59, no. 4, p. 046011, Feb. 2019.

[66] S. Brezinsek et al., 'Beryllium migration in JET ITER-like wall plasmas', Nucl. Fusion, vol. 55, no. 6, p. 063021, May 2015.

[67] A. Widdowson et al., 'M aterial migration patterns and overview of first surface analysis of the JET ITER-like wall', Phys. Scr., vol. T159, p. 014010, Apr. 2014.

[68] B. Schweer et al., 'Development of an ICRH antenna system at W 7-X for plasma heating and wall conditioning', Fusion Engineering and Design, vol. 123, pp. 303-308, Nov. 2017.

[69] A. Lyssoivan et al., 'ICRF plasmas for fusion reactor applications', Problems of Atomic Science and Technology, vol. 1, no. 13, 2007.

[70] T. Wauters et al., 'Ion and electron cyclotron wall conditioning in stellarator and tokamak magnetic field configuration on WEGA', AIP Conference Proceedings, vol. 1580, no. 1, pp. 187-190, Feb. 2014. 